\title{
17 Indigenous Studies with an Integrative Research Approach
}

\section{Introduction}

On the basis of the purpose of research, Management research can be characterized as either fundamental or applied. Here, fundamental research refers to a systematic study often undertaken to understand a phenomenon without specific application in mind (Legal Information Institute, 2021). Here the 'why' question is more dominant. Whereas, applied research is a form of systematic inquiry where the 'how' question is more dominant with the aim of gathering insights and knowledge towards directly realizing its benefits to practice.

Fundamental research is different in a way that it lays the foundation for further advancement in knowledge as modern scientific work is always a work in progress and scholars across the globe have conversations about fundamental features of a phenomenon through their publications. In applied research one tries to get access to accumulated theories, knowledge, methods, and techniques for specific management problems with a clear purpose to solve those problems (Roll-Hansen, 2009).

On the basis of the object of research, the process of knowing could be for a known thing or an unknown one. Consequently, fundamental research has two knowledge dimensions: "Knowing the known" and "Knowing the unknown". The two differ in the sense that for the former knowledge dimension, a researcher would focus on definitions as a starting point. Whereas in the latter, one would not start with a definition as it may not be existing or inadequate in the literature. Therefore, a researcher in the latter case of knowing the unknown, takes a broad view on the epistemology. This further may involve incorporating experiences (one's own as well as others') and tapping into the subjective realms of our being. While letting respondents express their experiences, the researcher tries to sense what it is about and induce a pattern from these experiences. Quite often, during the process of knowing a concept through deciphering this pattern, the knower encounters a split between two apparently opposing perspectives - Essentialism and Existentialism. For a researcher, even to fall into a particular philosophical category it requires an understanding to uncover existing ontological understanding of the phenomenon alongside the researcher's personal experience of the same phenomenon. Essentialism proposes a view that, for any specific entity (such as an animal, a group of people, a physical object, a concept), there is a set of attributes which are necessary to its identity and function. Whereas, existentialism holds that philosophical thinking 
begins with the human subject - not merely the thinking subject, but the acting, feeling, living human individual.

As a researcher with an integrative perspective as opposed to a dichotomous one, it may not be possible to position oneself completely into one of these philosophical categories. This is usually encountered during indigenous research in diverse contexts. In such a scenario, both a thinking perspective to define the attributes related to the topic as well as experiential perspective in the local context where the topic is being studied, are important (Panda \& Gupta, 2007). However, a non-indigenous (or universalist) study aims at an understanding of a phenomenon, where the theological and philosophical concepts have been assumed to have universal application, regardless of the local context. Is there an integrative research approach possible for studies that allow us to incorporate the non-universalistic dimension too? This means that we focus on the local context, its dynamics based on different purposes and perspectives of the entities in that context while we also connect to the underlying common ground of that local group based on their view of the world. An example could be a worldview which assumes that everything and everyone is connected at a deeper spiritual ground. Assuming this may lead to a researcher's choices towards search for the interconnectedness, which can be labeled as integrativeness. This has been the reason behind writing this book chapter. The chapter suggests a few building blocks for what one may call an integrative research approach by taking the case of leadership research through analysis of potential research methodologies. Subsequently we conclude with a discussion on how this topic can benefit from an indigenous research approach.

\section{Comparison of Research Methodologies}

Researchers before looking for fresh paradigms, need to acknowledge that there has always been an influence of dominant philosophy or worldview on the ways researchers conduct their research (Bindlish \& Nandram, 2019). This can be best shown by an example on the topic of leadership which has been studied for centuries now. There are various methodological issues raised in leadership research literature (Bindlish et al., 2019). Some of the approaches that had been attempted by leadership researchers can be broadly put under these categories namely: inductive, deductive and alternative ones.

1. Inductive approach: Bass and Stogdill (1981) studied 7500 references for his Handbook of Leadership, Rost (1991) studied 587 titles covering 221 definitions. There are plenty more definitions which still do not lead to a complete understanding, or which seems not broadly applicable or which may not hold for contemporary times (Walters, 2009). In a way, researchers seem to be looking for other newer approaches. As they are offering often the same perspective consequently leading to similar results. 
2. Deductive approach: Availability of enormous, rather endless, empirical data also is not able to provide an integrated understanding (Stodgill \& Bass, 1981). Researchers have expressed frustration over the growing amount of data which is not bringing us anywhere near to a detailed understanding of the concept of leadership. Empirical investigations for the last several decades of leadership research have not yielded an unequivocal conceptual understanding of leadership (Bennis \& Nanus, 1985). Infact, this was the view shared in the 1980s. After almost two decades, Vroom and Jago (2007) commented "Although this assertion is over 20 years old, our position is that any serious review of recent literature would reveal that the quote is as relevant today as it was then". On one hand this shows that there is skewness towards applied empirical research rather than fundamental conceptual research. On the other hand, some researchers felt that the leadership research lacked the right measures and was quite weak in research designs (Yukl, 1981)

3. Towards alternative approaches: Taking the quest further from above lines of thought, researchers explored other approaches. Some suggested using life stories as a valid way to explore the complexities of leadership. It was further argued that life stories incorporate diversity and interdisciplinary analyses thus promoting critical new methods of conceptualizing and researching leadership (Shamir et al., 2005). However biographies were argued to be better than an autobiography for leadership research citing that it is more reliable and less prone to leader's personal bias (Gronn, 2005). The traditional ways of studying leadership through traits and situations, have also been criticised for inability to produce sound scientific evidence adequate enough to guide practice (Vroom \& Jago, 2007). Although acknowledging that leadership understanding is problematic in various ways, many researchers expressed frustration over almost a century of non-yielding effort to find the holy grail of leadership. A few recent researchers have asked to introspect on whether we are searching for the right thing or not (Pye, 2005). To ascertain that, a few suggested that we step out of conventional western universalist mindset and explore leadership from eastern perspective, after setting aside our cherished conventional models for a moment altogether.

After studying the shortcomings of the existing approaches to leadership, the researcher encounters the following choices:

1. Same paradigms again: One may still get tempted to attempt the same way again, as the dominant worldview expressed in academic literature still welcomes research that follows the existing aspects of the dominant worldview and studies using new paradigms will not have many takers at places where it matters as they usually serve the same dominant worldviews.

2. Integration of philosophies or synthetic integration: One could attempt a moderate approach of proportionately mixing or assembling all approaches giving 
appropriate weightage (in some cases, democratic) to conventional approaches. This approach is being referred to here as an "integration of philosophies" based approach. Similar to a chemical mixture which retains the properties of its constituents, this integration retains the fundamental shortcomings like “data cranking null hypothesis rituals" (Cohen, 1994; Gigerenzer et al., 2004; Sedlmeier, 2009), skewness towards applied research and research designs casted in same dominant worldview.

It may also lead to perceptual errors because the perceptual units as viewed by actors in a worldview may be quite different as viewed by observers in a different worldview. An example is someone living in a linear worldview versus someone living in a cyclic worldview with the understanding that life does not stop with the death of our body in this life. The ignoring of different worldviews may lead to a fundamental attribution error.

Researchers invariably may underestimate the degree to which a person's behaviour reflects situational demands, which may determine his actions more powerfully than his personality. Managing diversity of worldviews among actors and researchers, is one of the most fundamental issues. This could be addressed and explored through a different approach. Researchers have observed that the synthesized worldview, in its attempt to bridge various worldviews, brings compromise between different practices emanating from those worldviews. This compromise mostly happens at systemic or framework level (Graen \& Wakabayashi, 1994). This option of the integration approach has become more dominant due to a reductionist view taken in social research design.

The growing usage of statistical tools (originally meant for material science such as physics) in social science and consequent usage of "hypothesis testing" increases this tendency. Although this has been criticised severely with strong evidence and arguments, labelling it as "null ritual", the practice is dominating the choices made by researchers for their scientific contributions. Although in contemporary models, not all studies require a hypothesis, Karl Popper's 'Theory of Empirical Falsification' (also known as 'Conjectures and Refutations') (Popper, 1963) is a popular example. Stacey’s complexity theory (Stacey et al., 2000) and Karl Weick’s sense-making theory (Weick et al., 2005) are some of the theories which philosophically seem to be going in that direction of an alternative research paradigm.

When one studies some characteristics of conventional methods of research derived from research methodology books of Cassell and Symon (2004); Huberman and Miles (2002); and Miles (1990) one can conclude that there are some shortcomings in these approaches: real life situations may not be explained, a lack of generalisability issues, and oversimplified views may be derived. Some aspects in reality might not be measurable as they occur over a long period of time. Sometimes theories may become leading while practice may be different. Furthermore the influence of the researcher in the research process may be taken into account as this may 
vary among researchers and therefore one may not find the same emerging patterns. Some researchers may rely too much on existing theories and therefore develop blind spots that are not seen during the research process leading to observation of the phenomenon partly. Even inductive methods such as grounded theory may show problems as theories that are built from scratch do not find opportunities to get validated, hypotheses are not developed to test at a later stage. This problem exists mainly because understanding the lived human experience is a time consuming activity and when a researcher has spent time studying this he may not have resources to do a follow up of validating outside the area of the substantive theory. This can happen in quasi experimental and single subject designs. Another problem is that in some types of methods such as historical and archival conflicting interpretations may be possible and generations may not exist to give the localized background information that may be required for a good interpretation of observations. Studies done in natural settings may have the weakness of having less control over the research. Action research may lead to biases and it may be a challenge to organize the administrative part which is required so that the researcher can play the role of facilitator and monitor the process. Content analysis and textual and hermeneutics may miss out the nonverbal information or the researcher may influence the choices that lead to emergence of meaning while other researchers may not agree with this meaning making process. Surveys, interviews and questionnaires may be superficial for some topics. Case studies and life stories are selections which may not be appreciated by other researchers. Most of these weaknesses can be mentioned if we intend to generalize or we want universalists' understanding. Seeing all such weaknesses it seems that transpersonal research approaches provide an alternative to cope with some of these. They acknowledge the researcher's experience and allow unique frameworks and experiences and do not intend generalizability.

Out of various research approaches available in social science and management, the transpersonal approaches are closer to addressing shortcomings in contemporary research. Some of the common transpersonal research approaches, conventional research approaches and disciplined methods of enquiry have been reviewed and presented in Table 17.1.

The dominant and non-dominant worldviews are not synthesizable and perhaps, non-integratable due to their natural differences like linear and nonlinear worldviews, cause-effect and effect-cause perspectives. Therefore, any integration of the above mentioned approaches would be synthetic in nature and may not even be possible. The paradigm leading to approaches of deduction of elements and summing up, would not lead to resolution to the research problem of for example leadership. Therefore an alternative approach is suggested by us labeled as integrative research approach. 
Table 17.1: Common transpersonal research approaches.

\begin{tabular}{llll}
\hline Approach & Description & Strengths & Weaknesses \\
\hline Integral Enquiry & $\begin{array}{l}\text { research is } \\
\text { multifaceted and } \\
\text { pluralistic }\end{array}$ & $\begin{array}{l}\text { Extensive and Intensive } \\
\text { study; tolerance for } \\
\text { ambiguity }\end{array}$ & $\begin{array}{l}\text { quality may be } \\
\text { compromised }\end{array}$ \\
\hline $\begin{array}{l}\text { intuition backed by } \\
\text { wide variety of data } \\
\text { collection and } \\
\text { analysis }\end{array}$ & $\begin{array}{l}\text { scope for incorporating } \\
\text { full dimensionality of } \\
\text { human knowing }\end{array}$ & $\begin{array}{l}\text { bias and prejudices of } \\
\text { research need to be } \\
\text { balanced by independent } \\
\text { researchers }\end{array}$ \\
\hline $\begin{array}{l}\text { Organic Research } \\
\text { story from } \\
\text { researcher's personal } \\
\text { experience }\end{array}$ & $\begin{array}{l}\text { exploration of topic in } \\
\text { which researcher has } \\
\text { interest; story telling and } \\
\text { listening }\end{array}$ & $\begin{array}{l}\text { may become } \\
\text { indistinguishable from a } \\
\text { novel !! }\end{array}$ \\
$\begin{array}{l}\text { Phenomenological } \\
\text { Enquiry }\end{array}$ & $\begin{array}{l}\text { transpersonal } \\
\text { awareness is } \\
\text { noumenal (devoid of } \\
\text { perception-as is) }\end{array}$ & $\begin{array}{l}\text { unique, strong } \\
\text { philosophical framework } \\
\text { and well articulated } \\
\text { methods }\end{array}$ & $\begin{array}{l}\text { explanation is not the } \\
\text { focus }\end{array}$ \\
$\begin{array}{l}\text { Informed } \\
\text { Exceptional } \\
\text { Human Experience } \\
\text { Enquiry }\end{array}$ & $\begin{array}{l}\text { focus on human } \\
\text { mystical, exceptional } \\
\text { experiences like } \\
\text { dreams }\end{array}$ & $\begin{array}{l}\text { thorough involvement of } \\
\text { researcher }\end{array}$ & $\begin{array}{l}\text { fear of it becoming a } \\
\text { dominant one ! }\end{array}$ \\
\hline
\end{tabular}

\section{Integrative Research Approach}

As discussed above, artificial or synthetic integration or unification of worldviews is not the right direction, as it sacrifices the indigenous nature of reality. The sacrificed portion is lost or in other words "digested" by the dominant paradigm. Therefore, an integrative research paradigm would be worth exploring. For the indigenous context, in the literature some approaches for conducting research have been mentioned such as de-colonizing views (Ashcroft et al., 2006; Dharampal, 1983) and using indigenous narratives (Cole, 2017). For integrative research however these may not be enough.

Bindlish et al. (2018) suggest a new approach where researchers prepare themselves mentally and spiritually before starting indigenous research using various techniques of social re-engineering as part of an integrative research approach (Bindlish et al., 2019). Nandram (2015) mentions that any research which is about understanding a phenomenon may benefit from a mental and spiritual preparation of the researcher in order to be clear in the mind for data collection in the field. Nandram mentions the mindful inquiry as a way to prepare oneself for a lucid observation and interpretation of what is being seen in a particular context (Nandram, 2013b). Understanding the worldview of the interviewee is an important element for 
getting a holistic view of the study. Suppose a person believes in the karma theory then it is important for the researcher to be aware of this as some actions in the person's mind may be scheduled for the future including future lives (Nandram, 2013a). For example in a study on stress the lack of stress may not be related to an intervention given but due to a person's worldview that he may have another future life to live and achieve the goals which he cannot achieve now. By ignoring this information we may make fundamental attribution errors.

For establishing an integrative research paradigm one can derive perspectives from Indian research methods which is labelled here as ancient Indian research methodologies. These emanate from a Vedic or so called dharmic worldview and can guide in studies that intend to take an alternative to the conventional hypothesis testing. There are plenty of interesting features of such methodologies. Let's take an example from the syllogism process for instance, "Phala-Hetu", it is about 'effect cause' in that order. It is a retrospective understanding of causation where one puts his effort first and then makes inferences of a possible cause (Malhotra, 2009).

Different from the universalistic paradigm, an integrative paradigm focuses on integral (not synthetic) unity without the nomothetic perspective of claiming generalizations at the manifest level (Nandram et al., 2019). Research following an integrative approach may ask for contemplations on fundamental aspects, thought experiments and inclusion of intuition, and indigenous explorations (Panda \& Gupta, 2007). It may also involve a departure from a typical psychologist or behaviorist's questionnaire style and could be more towards an open ended observational interview approach, which in practice, is more experienced than interviewing. The ancient Indian models do not explicitly divide research into fundamental and applied. The research, in general, is inclined towards discovering the real nature of the named concept (padārtha) and the fundamental constituent nature of the concept (tattva).

\section{The Process of Integrative Research}

Every indigenous context has many possibilities to enrich integrative research approaches. Here are a few aspects from ancient Indian research background. Any integrative research process involves one or more of these aspects:

1. Conviction (niścaya) - Here in general conviction for knowledge in search of truth, precedes the research. In other words, it is the researcher's conviction on "what is to be known". The researcher's conviction to know is the leading factor. This aspect of the integrative research paradigm brings focus back on that which is worth knowing and encourages theoretical thinking from different perspectives and scenarios of the process of knowing. This process of knowing comes from the framework of knowledge trinity (knower, knowable, knowledge) derived from Vedic wisdom (Bindlish et al., 2017, 2018; Nandram, 2019). 
A researcher who aims to study indigenous knowledge systems needs to have a conviction about it as it requires an open mind, engagement in that system, and participating in that system without knowing what he can expect regarding the quantity and quality of data sources and time that he has to spend to have a clear understanding. This part is inadequately addressed in the contemporary research paradigms.

2. Subject matter or object (jñēya) - This is the integral part of the conviction (niścaya). It is the end object, which is to be known or to be researched to know. This end object is also known as pramèya, an object to be known as per Nyāya philosophy, one of the six prominent Indian philosophical schools. This part resembles the process of defining one's research question where the researcher has chosen for a clear research focus after studying the extant literature. But in indigenous research using an integrative approach this studying of literature may not be always possible due to lack of sources in accessible ways and language. Like in many Indian scriptures there is no authorship and there are hundreds or even thousands of interpretations as they are localized due to context, living lineages, and languages.

3. Objective (prayojana) - At a broad abstract level, the objective could be the attainment of worldly goals (abhyudaya) or liberation (nihsśrēyasa) or a combination of both. Other objectives emanate from them. This understanding comes from an Indian philosophy known as Vaiśeșika philosophy. In further categorization, the objective could be one or more from the four life goals as per Hindu worldview: righteousness (dharma) means for prosperity (artha), worldly or material desires (kama), and emancipation or liberation (mokșa). The first three are part of worldly goals (abhyudaya) and the last one is a spiritual goal (nihsśrēyasa). In contemporary research these broad categories of objectives are not thought about when conducting the research but for the theme of spirituality it is an important objective. In contemporary context this process can be equated with the problem statement and management problem that the researcher is trying to solve which will always be related to worldly goals.

Every research is expected to be clear on the objective in this manner as the subject matter (jñèya) and objective (prayōjana) are integral parts of the conviction (niścaya) of the researcher who follows an integrative research paradigm. At a secondary level, the researcher may additionally develop curiosity ( $i j n \tilde{a} \bar{a} s \bar{a}$ ) or doubt (samśaya). The resolution of the curiosity or clarification of the doubt could be a secondary objective for research.

4. Thesis (siddhānta) - This is the final compilation or presentation of the knowledge of the subject matter (jñeya). Usually, it has statements established using one or more research methods (yukti). The thesis principles (siddhānta) may have three components: the aspect of the named concept which is to be known (pakșa); the reasoning of syllogism used (hētu); and the evidence for used syllogism (drșțānta). 
On the basis of the applicability, the principles (siddhānta) are categorized into either a principle applicable everywhere (sarvatantra siddhānta) or a principle applicable in a particular context (pratitantra siddhānta). This part of the process resembles the research design and generalizability in modern research paradigms. The interesting pattern here is that in modern paradigms we may talk about external validity but still we may be cautious about the context to which the validity is attributed to while the principle of sarvatantra siddhānta in the integrative paradigm is more conclusive. Another interesting pattern is that in an integrative research approach the applicability to a particular context (pratitantra siddhānta) is also appreciated as universal applicability which brings the balance which otherwise often is lacking in contemporary research designs.

5. Integrative review (samanvaya) - The research in a Indian model always ends up with a philosophical reconciliation process. The underlying assumption is the interconnectivity of all living and nonliving beings. During this process the thesis is therefore viewed from various perspectives and objections are removed in a manner that all have a common understanding of the subject matter (jñêya). This process of reconciliation may require a process of dialogue (śāstrārtha) which is sometimes misinterpreted as "debate" or "defense". This is a process that aims at arriving at an acceptable understanding of the description of object or reality. This process has three components: researcher's position on the subject matter (pakșa); the reason (hetu); and the evidence or syllogism (drssțānta).

It is worth mentioning that the researcher's position often does not get a prominent place in contemporary research approaches. This part of the process is comparable with the conclusion and discussion aspect in contemporary approaches. However the intent to reconcile seems exclusive in the integrative approach. In other approaches critique is the driving force of developing new insights and comparison with the already dominating worldview is the way to conclude a research while here there is no dominant or less-dominant worldview, different perspectives and purposes of entities are intentionally included for a specified context as a major part of the research. Furthermore, this process of samanvaya invites for a reflection on the findings from the side of the researcher as his experiences are also given space in an integrative research approach.

\section{Conclusion}

The important research aspects for understanding indigenous phenomena can be found in an integrative paradigm, derived from ancient Indian research methods, which seemed to be missing or less highlighted in conventional approaches. Usually in dominant research paradigms there is less relevance given to conviction 
(niścaya) and the positioning of the researcher (pakșa) while these are important contributions to experience the topic of research as an integrative approach gives spaces for inclusion of both objective realities and subjective experiences. Furthermore in conventional approaches, there is a limited subject matter (jñêya) and objectives (prayōjana) are not incorporated holistically by including worldly and spiritual goals. Another conclusion is that in conventional approaches there is a limited integrative review (samanvaya). Yet another conclusion is that the integrative approach gives space for both local (pratitantra siddhānta) and universal applicability (sarvantantra siddhānta). The whole research process should be followed by a complete review of several aspects, perspectives and purposes that are relevant for the subject matter in order to reconcile. If a research paradigm is able to integrate these aspects, then it can be called an integrative research approach which will be beneficial to both modern and indigenous phenomena in social context.

\section{References}

Ashcroft, B., Griffiths, G., \& Tiffin, H. (2006). The Post-Colonial Studies Reader. Routledge.

Bass, B. M., \& Stogdill, R. (1981). Handbook of leadership. Theory, research, and managerial. The Free Press. New York.

Bennis, W., \& Nanus, B. (1985). The strategies for taking charge. Leaders, New York: Harper. Row, 41.

Bindlish, P. K., \& Nandram, S. S. (2019). Manifestation of worldview in a metaphor. International Journal of Business and Globalisation, 23(3), 464474. https://doi.org/10.1504/ IJBG.2019.102925

Bindlish, P. K., Nandram, S. S., \& Gupta, R. K. (2019). Definition schema for redefining leadership: An integrative approach. International Journal of Indian Culture and Business Management, 18 (1), 34-58. https://doi.org/10.1504/IJICBM.2019.096921

Bindlish, P. K., Nandram, S. S., Gupta, R. K., \& Joshi, A. (2018). How to prepare the researcher for indigenous context: An integrative approach. International Journal of Indian Culture and Business Management, 17(2), 221-237. https://doi.org/10.1504/IJICBM.2018.094255

Bindlish, P. K., Nandram, S. S., \& Joshi, A. (2017). Integrative intelligence as the path forward. In S. S. Nandram \& P. K. Bindlish (Eds.), Managing VUCA Through Integrative Self-Management (pp. 263-287). Springer.

Cassell, C., \& Symon, G. (2004). Essential Guide to Qualitative Methods in Organizational Research. Sage.

Cohen, J. (1994). The earth is round (p<. 05). American Psychologist, 49(12), 997-1003.

Cole, P. (2017). An Indigenous research narrative: Ethics and protocols over time and space. Qualitative Inquiry, 23(5), 343-351. https://doi.org/10.1177/1077800416659083

Dharampal. (1983). The Beautiful Tree: Indigenous Education in the Eighteenth Century. Biblia Impex.

Gigerenzer, G., Krauss, S., \& Vitouch, O. (2004). The null ritual. What you always wanted to know about significance testing but were afraid to ask. In D. Kaplan (Ed.), Sage Handbook of Quantitative Methodolgy for Social Sciences (pp. 391-408). 
Graen, G. B., \& Wakabayashi, M. (1994). Cross-cultural leadership making: Bridging American and Japanese diversity for team advantage. In H. C. Triandis \& L. M. Hough (Eds.), Handbook of Industrial and Organizational Psychology (Vol. 4, pp. 415-446). Consulting Psychologists Press Palo Alto, CA.

Gronn, P. (2005). Leading questions: Questions about autobiographical leadership. Leadership, 1 (4), 481-490.

Huberman, M., \& Miles, M. B. (2002). The Qualitative Researcher's Companion. Sage.

Legal Information Institute. (2021). Cornell Law School. http://www.law.cornell.edu/cfr/text/32/ 272.3

Malhotra, R. (2009). Integral Unity and Synthetic Unity: Being Different. Harper Collins.

Miles, M. B. (1990). New methods for qualitative data collection and analysis: Vignettes and prestructured cases. International Journal of Qualitative Studies in Education, 3(1), 37-51. https://doi.org/10.1080/0951839900030104

Nandram, S. S. (2013a). Karma theory. In D. Coghlan \& M. Brydon-Miller (Eds.), The Sage Encyclopedia of Action Research (pp. 475-477). SAGE Publications.

Nandram, S. S. (2013b). Mindful inquiry. In D. Coghlan \& M. Brydon-Miller (Eds.), The Sage Encyclopedia of Action Research (pp. 537-540). SAGE Publications.

Nandram, S. S. (2015). Organizational Innovation by Integrating Simplification: Learning from Buurtzorg Nederland. Springer International Publishing. https://doi.org/10.1007/978-3-31911725-6

Nandram, S. S. (2019). Integrative Spirituality in the Fourth Industrial Revolution: From How We Do Things to Why We Exist. Vrije University Press. https://research.vu.nl/en/publications/integra tive-spirituality-in-the-fourth-industrial-revolution-from

Nandram, S. S., Bindlish, P. K., Purohit, H., Joshi, A., \& Hingorani, P. (2019). Foundations for social entrepreneurship: An integrative Indian perspective. In L. Bouckaert \& S. C. van den Heuvel (Eds.), Servant Leadership, Social Entrepreneurship and the Will to Serve (pp. 161-186). Palgrave Macmillan.

Panda, A., \& Gupta, R. K. (2007). Call for developing indigenous organisational theories in India: Setting agenda for future. International Journal of Indian Culture and Business Management, 1 (1/2), 205-243. https://doi.org/10.1504/IJICBM.2007.014478

Popper, K. R. (1963). Science as falsification. Conjectures and Refutations, 1(1963), 33-39.

Pye, A. (2005). Leadership and organizing: Sensemaking in action. Leadership, 1(1), 31-49. https://doi.org/10.1177/1742715005049349

Roll-Hansen, N. (2009). Why the Distinction Between Basic (Theoretical) and Applied (Practical) Research is Important in the Politics of Science. London School of Economics and Political Science, Contingency and Dissent in Science Project.

Rost, J. C. (1991). Leadership for the Twenty-First Century. Greenwood Publishing Group.

Sedlmeier, P. (2009). Beyond the significance test ritual: What is there? Zeitschrift für Psychologie/ Journal of Psychology, 217(1), 1-5. https://doi.org/10.1027/0044-3409.217.1.1

Shamir, B., Dayan-Horesh, H., \& Adler, D. (2005). Leading by biography: Towards a life-story approach to the study of leadership. Leadership, 1(1), 13-29. https://doi.org/10.1177/ 1742715005049348

Stacey, R. D., Griffin, D., \& Shaw, P. (2000). Complexity and Management: Fad or Radical Challenge to Systems Thinking? Psychology Press.

Stodgill, R. M., \& Bass, B. M. (1981). Stogdill's Handbook of Leadership. A Survey of Theory and Research. Macmillan.

Vroom, V. H., \& Jago, A. G. (2007). The role of the situation in leadership. American Psychologist, 62(1), 17-24. https://doi.org/10.1037/0003-066X.62.1.17 
Walters, D. C. (2009). Exploring a definition of leadership and the biography of Dr. Frank B. Wynn. ProQuest Dissertations and Theses, Order No. 3360170, University of Montana, 317.

Weick, K. E., Sutcliffe, K. M., \& Obstfeld, D. (2005). Organizing and the Process of Sensemaking

(5th ed., Vol. 16). Prentice Hall. http://pubsonline.informs.org/doi/abs/10.1287/orsc.1050. 0133

Yukl, G. (1981). Leadership in Organizations (5th ed.). Prentice Hall. 